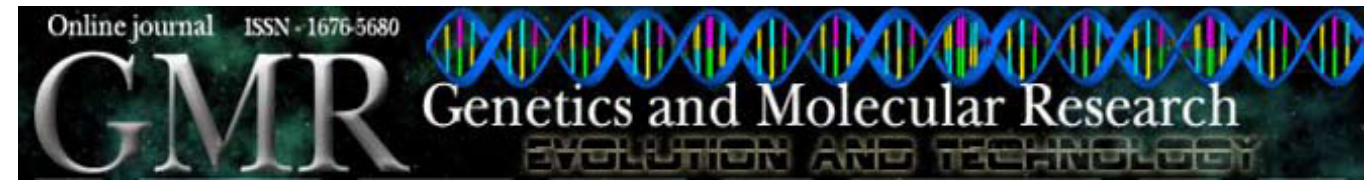

\title{
Major congenital anomalies: a five-year retrospective regional study in Turkey
}

\author{
A.G. Tomatır' ${ }^{1}$ H. Demirhan², H.Ç. Sorkun², A. Köksal², \\ F. Özerdem ${ }^{3}$ and N. Çilengir ${ }^{3}$ \\ ${ }^{1}$ Department of Medical Biology, Pamukkale University Medical Faculty, \\ Denizli, Turkey \\ ${ }^{2}$ Pamukkale University Health Services Vocational School, Denizli, Turkey \\ ${ }^{3}$ Physicians of Turkish Ministry of Health, Denizli, Turkey \\ Corresponding author: A.G. Tomatir \\ E-mail: tomatir@pau.edu.tr or aysegaye@hotmail.com
}

Genet. Mol. Res. 8 (1): 19-27 (2009)

Received October 6, 2008

Accepted October 21, 2008

Published January 13, 2009

\begin{abstract}
We examined the distribution and demographic characteristics of congenital anomalies in a Turkish province for five years. The records of 63,159 live births between 2000 and 2004 were examined retrospectively. Major congenital anomalies were classified according to year, organ system, gender, family relationship, maternal age, mortality rate, and method of delivery. There were 183 cases of major birth defects among 63,159 live births, giving a prevalence of $2.9 / 1000$. Anomalies of the central nervous system were the most common defect (31\%), followed by cleft palate/lip (19\%), musculoskeletal system anomalies (14\%), and chromosomal anomalies (13\%). Among the infants with major anomalies, $14 \%$ did not survive, 56\% were delivered vaginally, and $25 \%$ were miscarried. There was a significant increase in rate of major congenital anomalies during the five-year period.
\end{abstract}

Key words: Congenital anomalies; Retrospective study 


\section{INTRODUCTION}

Congenital anomalies are one of the most common causes of disability in developed and developing countries (EUROCAT Working Group, 2002). It is clear that research is an important component of medical genetics. However, data on congenital anomalies from population-based studies originating from developing countries are largely lacking (Thong et al., 2005); there are insufficient data currently available on the epidemiology of genetic disorders, the demand for genetic services, and the quality, use and outcomes of genetic services in developing countries (WHO, 1999).

Since the 1960s, a general surveillance has been carried out monitoring the appearance of congenital anomalies in various populations around the world (Blomberg et al., 2000). Worldwide surveys have shown that the birth prevalence of congenital anomalies varies greatly from country to country (Temtamy et al., 1998; Bloomberg et al., 2000; Shi et al., 2002; Biri et al., 2005); it is reported to be as low as 1.07\% in Japan and as high as $4.3 \%$ in Taiwan (Temtamy et al., 1998). In the US, where most research has been conducted on this subject, a 2-3\% birth prevalence of congenital anomalies has been reported. The birth prevalence of congenital anomalies in England is 2\% and in South Africa it is $1.49 \%$ (Biri et al., 2005). These variations may be explained by social, racial, ecological, and economical influences (Temtamy et al., 1998; Biri et al., 2005).

In a study conducted in Turkey, a congenital anomaly birth prevalence of $2 \%$ was found. This number only includes anomalies that were recognized at birth; the percentage increased to $5 \%$ when renal and cardiac system anomalies, which were diagnosed later, were added (Apak, 1992). In a study conducted by Tunçbilek et al. (1999) in Turkey, the birth prevalence of all anomalies was similar to other countries, but there was a higher prevalence of neural tube defects and cleft palate/lip. In the etiology of anomalies, approximately $10-20 \%$ were shown to be genetic, $10-20 \%$ environmental, and $60-80 \%$ were attributed to unknown factors. In the examination of newborns with congenital anomalies, prevalences of $3 \%$ for single major anomaly and $0.7 \%$ for multiple major anomalies have been reported (Aksoy, 2001). It has also been shown that 12.3-32\% of deaths that occur during the perinatal period are related to congenital anomalies (Aksoy, 2001). According to data from TNSA in Turkey in 2003, the rate of perinatal mortality is 24 in 1000 and that of infant mortality is 29 in 1000 . Amongst women between 15 and 49 years of age, the rate of childbirth is 2.23 in 1000, and women who are under 20 years of age and over 35 are responsible for $22 \%$ of all births (TNSA, 2003).

The control of genetic diseases should be based on an integrated and comprehensive strategy combining the best possible treatment and prevention through community education, population screening, genetic counseling, and the availability of early diagnosis (WHO, 2005). Some of the most common genetic diseases (thalassemias, cystic fibrosis, hemophilia, and phenylketonuria) can be managed with considerable success (WHO, 2005). The prevalence of beta-thalassemia in Denizli has been successfully controlled with the cooperation of two facilities, the Turkish Ministry of Health and Pamukkale University. The beta-thalassemia prevalence in Denizli is between 2.6 and 3.7\%, as reported by different researchers (Y1ldiz et al., 2005).

Efficient surveillance systems (registries and databases) and continued investment in genetic research are fundamental to successful public health interventions, particularly 
in low-resource settings (WHO, 2005). However, there is no ongoing surveillance system of congenital anomalies in Turkey (Mandıracioğlu et al., 2004). In addition, because Turkey still lacks a genetic service network and because there is a deficit in terms of genetic counseling for preventive health services and in properly trained health care personnel who can provide these services (Tomatır et al., 2006a,b, 2007), the prevalence of congenital anomalies is negatively affected.

To control the different types of congenital anomalies and their prevalence in every society, it is important that the distribution and prevalence of congenital anomalies are identified for every country, and even for every region (Biri et al., 2005). The objective of the present study was to determine the distribution and demographic characteristics of congenital anomalies recorded over five years in Denizli province, and to contribute to the efforts in their screening, diagnosis and treatment.

\section{SUBJECTS AND METHODS}

This population-based, descriptive study of major congenital anomalies was planned with close cooperation with the Turkish Ministry of Health. The permission and cooperation of the Denizli Province Health Minister and Ethics Committee approval were also obtained for this study.

The site of this study, Denizli, is located in the interior section of Turkey's Aegean region. Denizli province is in western Turkey; apart from the city of Denizli, it is made up of 18 towns and 372 villages. The provincial capital have a total population of 323,151 , while the villages have a total population of 171,810 , making a total population for the area of 907,325 people, of whom 453,756 are men and 453,569 are women [http://www.denizli.gov.tr/denizli/ genelbilgiler.htm\#NÜFUS].

All families and individuals living in the provincial center and the dependent boroughs are registered once a year by health centers linked to the council health service. Once the provincial population has been established, each family receives a health visit twice a year if there is no pregnancy and at least six times a year in the period leading up to the birth by a midwife if there is a pregnancy. In the first year after the birth, the mother and the baby have at least eight check-ups with a midwife and a doctor. Major congenital anomalies identified during these check-ups are recorded on infant and child medical forms. All public health clinics in the urban and rural areas of Denizli province were examined and midwives were interviewed for this study. The data were recorded on standard forms developed by the researchers over the period from February 1 to May 31, 2005. The records of 63,159 live births from the years 2000-2004 were examined retrospectively. The anomalies were then grouped according to year, organ system, gender, maternal age, consanguinity, mortality rate, and mother's natal history. Anomalies were determined and classified according to ICD-10 (WHO, 1992). Cases where more than one birth anomaly was recorded (related to the digestive tract, circulation system, the extremities, intelligence, and hearing or sight problems, as well as spastic and autistic cases) were put in the miscellaneous group. Cases of enzyme and immune deficiency were grouped as other anomalies. Pregnancies, which were terminated because of fetal anomalies and stillbirths, were not included in the study.

Statistical analysis was performed by the chi-square test, and mean and percent- 
age values were calculated. $\mathrm{P}<0.05$ was considered to be statistically significant.

\section{RESULTS}

There were 183 cases $(2.9 / 1000)$ of single or multiple congenital anomalies among 63,159 live births that occurred during the years 2000-2004. The most common anomalies were related to the nervous system (31.1\%), cleft palate and lip (18.6\%), musculoskeletal system disorders (14.2\%), and chromosomal anomalies (13.1\%) (Figure 1). An increase was seen in the live birth prevalence of major anomalous births year to year $(\mathrm{P}<0.01)$ (Figure 2). Males comprised $54.1 \%$ of anomalous births, and one infant was born with both female and male sexual organs. Both genders were found to have greater anomalies related to the nervous system (34.9\% of girls and $28.3 \%$ of boys), while amongst girls the next most common anomalies were found to be cleft palate and lip (20.5\%) and chromosomal anomalies (15.7\%), and amongst boys the next most common were musculoskeletal system anomalies $(19.2 \%)$ and cleft palate and lip $(17.2 \%)(\mathrm{P}>0.05)$.

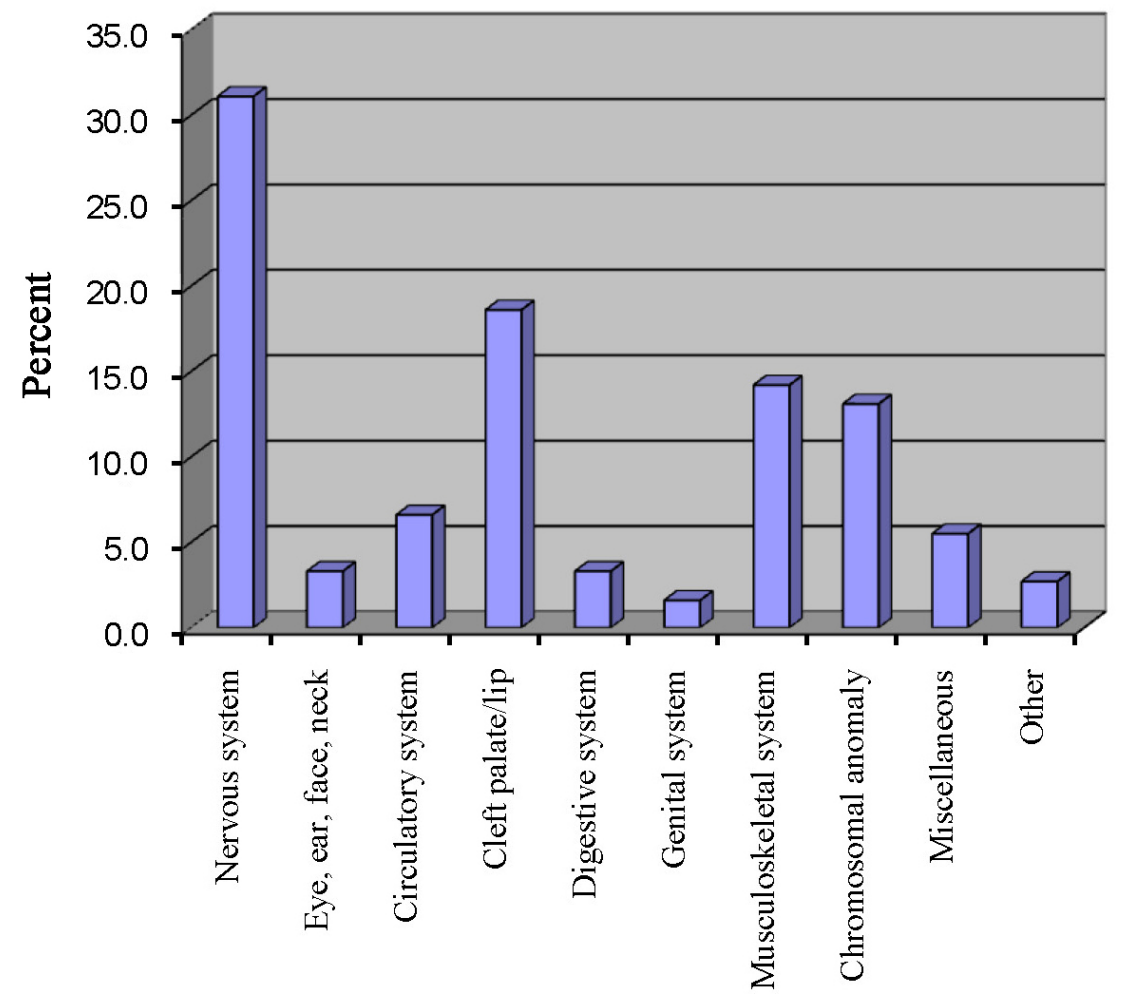

Figure 1. Distribution of anomalies by systems. 


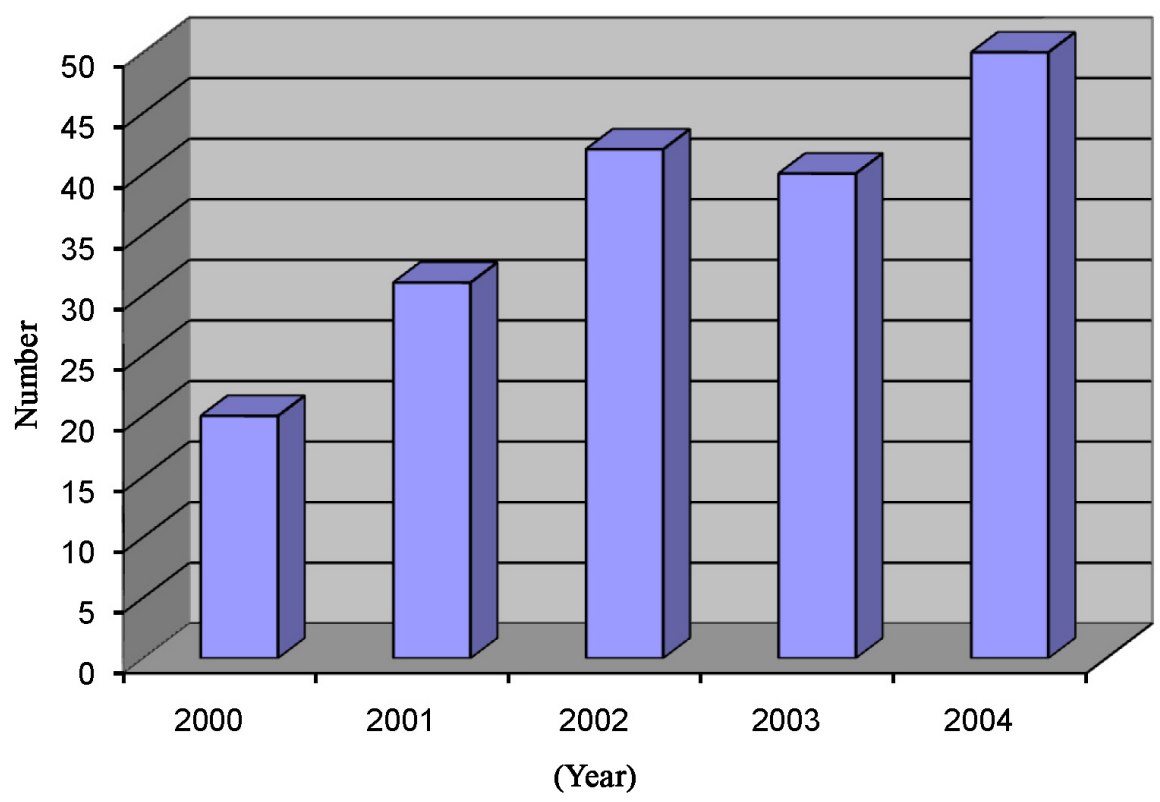

Figure 2. Distribution of anomalies by year.

Among the infants with major anomalies, $14.3 \%$ were from consanguineous marriages, of which $8.2 \%$ were born to adolescent mothers, $8.7 \%$ were from older mothers (aged over 34 years), and $14.3 \%$ did not survive (Table 1). Of the anomalies resulting from consanguineous marriages, $46.2 \%$ were found to be of the nervous system; the next most common anomalies were found to be of the circulatory system, musculoskeletal system and miscellaneous group, at $11.5 \%$. When considering mortality rate for anomalous births, $33.3 \%$ of infants born with digestive system anomalies, $28.6 \%$ with nervous system problems, and $20 \%$ of the miscellaneous group did not survive. Of births to mothers in the risk group - adolescents under the age of 20 and women 35 and over - $16.9 \%$ were found to be anomalous. Of births to adolescent mothers, the largest proportion of anomalies were found to be those affecting the nervous system (46.7\%) and cleft palate and lip (26.7\%); in the 35 and over group, nervous system (37.5\%) and chromosomal anomalies $(31.3 \%)$ were more noticeable. The proportion of nervous system anomalies $(28.9 \%)$ found in mothers in the normal age group was lower than in mothers in the risk group $(\mathrm{P}>0.05)$.

In the risk group, $25.8 \%$ of babies born with anomalies died, but of the anomalous births to mothers in the 20-34 age bracket, a lower rate of infant mortality (11.9\%) was found. Based on health service records of infant deaths in the province in the last five years, 1090 infants died before completing their first year.

Of mothers who experienced anomalous births, $22.4 \%$ were found to have had an earlier abortion while $21.3 \%$ had lost at least one child. For $78.1 \%$ of these mothers, it was their first or second live birth (Table 2). In the examination of the natal data of the mothers of infants with a congenital anomaly, it was determined that $55.7 \%$ were delivered vaginally. 


\begin{tabular}{|c|c|c|}
\hline Characteristic & $\mathrm{N}$ & $\%$ \\
\hline \multicolumn{3}{|l|}{ Gender } \\
\hline Female & 83 & 45.4 \\
\hline Male & 99 & 54.1 \\
\hline Ambiguous genitalia & 1 & 0.5 \\
\hline \multicolumn{3}{|c|}{ Family history: consanguinity } \\
\hline Yes & 26 & 14.3 \\
\hline No & 156 & 85.2 \\
\hline Unknown & 1 & 0.5 \\
\hline \multicolumn{3}{|l|}{ Maternal age } \\
\hline$\leq 19$ years & 15 & 8.2 \\
\hline 20-34 years & 152 & 83.1 \\
\hline$\geq 35$ years & 16 & 8.7 \\
\hline \multicolumn{3}{|l|}{ Mortality } \\
\hline Alive & 156 & 85.2 \\
\hline Dead & 26 & 14.3 \\
\hline Unknown & 1 & 0.5 \\
\hline Total & 183 & 100.0 \\
\hline
\end{tabular}

\begin{tabular}{lrr} 
Table 2. Distribution of mothers' perinatal data. & & \\
\hline Characteristic & $\mathrm{N}$ & $\%$ \\
\hline Number of miscarriages & & \\
None & 138 & 75.4 \\
1 & 31 & 16.9 \\
2 & 8 & 4.4 \\
$>3$ & 2 & 1.1 \\
Unknown & 4 & 2.2 \\
Deceased children & & \\
None & 140 & 76.5 \\
1 & 32 & 17.5 \\
2 & 4 & 2.2 \\
$>3$ & 3 & 1.6 \\
Unknown & 4 & 2.2 \\
Number of live births & & \\
1 & 72 & 39.3 \\
2 & 71 & 38.8 \\
3 & 20 & 10.9 \\
4 & 6 & 3.3 \\
$>5$ & 10 & 5.5 \\
Unknown & 4 & 2.2 \\
Total & 183 & 100.0 \\
\hline
\end{tabular}

\section{DISCUSSION}

Most children who are born with major congenital anomalies and survive infancy are affected physically, mentally or socially and can be at increased risk of morbidity due to various health disorders (Queisser-Luft et al., 1998; WHO, 2000; Correa-Villaseñor et al., 2003). While the prevalence of congenital anomalies at birth in developed countries is reported to be 
between 3-5\%, those reported in Turkey before the 1990s were in general lower than this figure (Göynümer et al., 2005). However, a study that investigated the number of all infants born in one year with a congenital anomaly at 22 university hospitals in Turkey found a birth prevalence of congenital anomalies of $3.65 \%$ (Tunçbilek et al., 1999). The prevalence of congenital anomalies for the Denizli region in this study was reported to be 2.9 per 1000 births. The most common anomalies were related to the nervous system (31.1\%), cleft palate and lip (18.6\%), musculoskeletal system disorders (14.2\%), and chromosomal anomalies (13.1\%). The most common type of anomaly reported in this study, as in other national and international studies, was central nervous system anomalies (De Galan-Roosen et al., 1998; Tunçbilek et al., 1999). According to Tunçbilek et al. (1999), central nervous system anomalies comprise $40 \%$ of all anomalies. One possible explanation for the apparent higher percentage of these types of defects may be because they are obvious at birth and are recorded more carefully than other defects (Göynümer et al., 2005). According to the study by Tunçbilek et al. (1999), the most common systems affected by anomalies after the central nervous system are the urinary (14.4\%), musculoskeletal (11.70\%) and cardiovascular (8.28\%) systems. In this study, after central nervous system anomalies, the most common anomalies were cleft palate/lip, musculoskeletal system anomalies and chromosomal anomalies. Defects of the face such as cleft palate/lip are seen in every 600-800 live births. In $60 \%$ of the cases, they occur together with other anomalies (Biri et al., 2005). Skeletal system anomalies have an important place in congenital anomalies and their early diagnosis is important because some of them can be lethal. Their prevalence is reported to be $1 / 210$ in the perinatal period (Göynümer et al., 2005). In another study by Himmetoğlu et al. (1996) in a Turkish population, a prevalence of $1.11 \%$ was found for all congenital anomalies, with neural tube defects in first place, urogenital system anomalies second, facial anomalies third, and musculoskeletal system anomalies fourth. In an 11-year retrospective study of records in Bahrain, a live birth prevalence of congenital anomalies of $2.7 \%$ was found. Among the anomalies, the musculoskeletal system had the highest prevalence ( 2.28 per 1000), followed by those affecting the genitourinary system (2.13 per 1000), while the prevalence of chromosomal disorders was 0.9 per 1000 (Al Arrayed, 1995). Temtamy et al. (1998) reported that the birth prevalence of congenital anomalies among 3000 hospital births was 3.17\% (31.67/1000 total births) in Egypt. Other studies among live-born neonates showed different prevalence figures: in Spain it was 20.23 per 1000, in Libyan Arab Jamahiriya 23.8 per 1000, in India 27.2 per 1000, and in WHO centers covering 16 countries it was 12.7 per 1000 (Temtamy et al., 1998).

The gender of the fetus did not affect the prevalence of congenital anomalies, and both genders were equally distributed. These findings are consistent with Biri et al. (2005). In this study, $14.3 \%$ of the parents were consanguineous. The site of this study, Denizli province in western Turkey, has an 11.7\% incidence of consanguineous marriages (Şimsek et al., 1999), which is lower than the general incidence in Turkey of consanguineous marriages (20-25\%) (Tunçbilek, 2001).

Maternal age is an important parameter in the birth of a congenitally malformed fetus (Hollier et al., 2000). For this reason, the risk of birth of a congenitally malformed fetus in mothers who are older than 35 years of age needs to be examined more carefully. In Turkey, 5.2\% of mothers are older mothers, that is, they are 35 years of age or older (TNSA, 2003). In this study, $8.7 \%$ of anomalous births were from older mothers, although this was not statistically significant.

In the present study, the mortality rate for congenital anomalous births was determined to be $14.7 \%$. In the cases in our study, we did not have any autopsy findings. In comparison with developed countries, etiological factors and final diagnoses are incomplete for 
Turkey because permission is not granted to perform an autopsy in research centers, even after perinatal deaths (Göynümer et al., 2005). De Galan-Roosen et al. (1998) found that congenital anomalies of the central nervous system are mostly lethal in the stillbirth group (45\%). Cardiovascular and pulmonary defects were more prominent in the neonatal period. Urogenital and minor anomalies (miscellaneous) are more often seen in perinatal deaths without being a contributor to the cause of death (De Galan-Roosen et al., 1998).

In conclusion, the most common congenital anomalies in Denizli in the last five years are, respectively, nervous system anomalies, cleft palate and lip, musculoskeletal system anomalies, and chromosomal anomalies. The low birth prevalence of congenital anomalies ( 2.9 per 1000 births) in this study may be a result of inadequate prenatal and postnatal examination and autopsy findings, as well as personal and institutional characteristics of the current documentation system. In the records for the five years investigated in this study, we found a steady increase in the number of anomalies. There is a need for new studies to investigate the reasons for this increase over recent years. In addition to this, there is also a need for more extensive, nationwide screening studies to determine the birth prevalence, types and distribution of congenital anomalies in the Turkish population. The lack of an ongoing surveillance system for congenital anomalies in Turkey, coupled with having neither a genetic service network, genetic counseling for preventive health services, nor properly trained health care personnel to provide these services, has had a negative effect on the prevalence of congenital anomalies. To eliminate all of these deficiencies, various national and institutional steps need to be taken.

\section{ACKNOWLEDGMENTS}

We would like to thank the Turkish Ministry of Health for helpful comments on this paper.

\section{REFERENCES}

Aksoy F (2001). Konjenital anomaliler: Tanimlama, siniflama, terminoloji ve anomalili fetusun incelenmesi. (Congenital anomalies: description, classification, terminology and examination of fetus with congenital anomalies). Türk Patol. Dergisi 17: 57-62.

Al Arrayed SS (1995). Epidemiology of congenital abnormalities in Bahrain. East. Mediterr. Health J. 1: 248-252.

Apak MY (1992). Approach to Genetic Diseases and Genetic Counseling. In: Prenatal Diagnosis and Management (Aydinli K, ed.). Perspektif Yayin, Istanbul, 1-18.

Biri A, Onan A, Korucuoglu Ü, Tiras B, et al. (2005). Bir üniversite hastanesinde konjenital malformasyonların görülme sıklığı ve dağılımı (Birth prevalence and distribution of congenital anomalies in a university hospital). Perinatol. Dergisi 13: 86-90.

Blomberg M, Selbing A and Kallen B (2000). Congenital malformations in the southeast of Sweden - a registry study with validation. Acta Paediatr. 89: 1238-1243.

Correa-Villaseñor A, Cragan J, Kucik J, O’Leary L, et al. (2003). The Metropolitan Atlanta Congenital Defects Program: 35 years of birth defects surveillance at the Centers for Disease Control and Prevention. Birth Defects Res. A. Clin. Mol. Teratol. 67: 617-624.

De Galan-Roosen AE, Kuijpers JC, Meershoek AP and van Velzen D (1998). Contribution of congenital malformations to perinatal mortality. A 10 years prospective regional study in The Netherlands. Eur. J. Obstet. Gynecol. Reprod. Biol. 80: 55-61.

EUROCAT Working Group (2002). Surveillance of congenital anomalies in Europe 1980-1999. EUROCAT Report 8. Universty of Ulster, Belfast.

Göynümer FG, Kepkep K, Yetim G, Tuncay Y, et al. (2005). Dogumlarda Majör Konjenital Anomalilerin Retrospektif Analizi (Retrospective analysis of major congenital anomalies at birth). Perinatol. Dergisi 13: 31-34. 
Himmetoğlu O, Tiras MB, Gursoy R, Karabacak O, et al. (1996). The incidence of congenital malformations in a Turkish population. Int. J. Gynaecol. Obstet. 55: 117-121.

Hollier LM, Leveno KJ, Kelly MA, McIntire DD, et al. (2000). Maternal age and malformations in singleton births. Obstet. Gynecol. 96: 701-706.

Mandiracioğlu A, Ulman I, Lüleci E and Ulman C (2004). The incidence and risk factors of neural tube defects in Izmir, Turkey: a nested case-control study. Turk. J. Pediatr. 46: 214-220.

Queisser-Luft A, Stopfkuchen H, Stolz G, Schlaefer K, et al. (1998). Prenatal diagnosis of major malformations: quality control of routine ultrasound examinations based on a five-year study of 20,248 newborn fetuses and infants. Prenat. Diagn. 18: 567-576.

Shi LM, Chia SE, Chan OY, Chew SK, et al. (2002). Prevalence of birth defects and parental work in Singapore live births from 1994 to 1998: a population-based study. Occup. Med. 52: 325-331.

Şimsek S, Ture M, Tugrul B, Mercan N, et al. (1999). Consanguineous marriages in Denizli, Turkey. Ann. Hum. Biol. 26: 489-491.

Temtamy SA, Abdel Meguid N, Mazen I, Ismail SR, et al. (1998). A genetic epidemiological study of malformations at birth in Egypt. East. Mediterr. Health J. 4: 252-259.

Thong MK, Ho JJ and Khatijah NN (2005). A population-based study of birth defects in Malaysia. Ann. Hum. Biol. 32 : 180-187.

TNSA, Hacettepe University, Institute of Population Studies and Macro International Inc. (2003). Turkish Demographic and Health Survey (DHS-2003). Available at [http://www.hips.hacettepe.edu.tr/tnsa2003/anaraporenglish.htm]. Accessed January 2006.

Tomatir AG, Özsahin A, Sorkun HÇ, Demirhan H, et al. (2006a). Midwives' approach to genetic diseases and genetic counseling in Denizli, Turkey. J. Genet. Couns. 15: 191-198.

Tomatir AG, Sorkun HC, Demirhan H and Akdag B (2006b). Nurses' professed knowledge of genetics and genetic counseling. Tohoku J. Exp. Med. 210: 321-332.

Tomatir AG, Sorkun HC, Demirhan H and Akdag B (2007). Genetics and genetic counseling: practices and opinions of primary care physicians in Turkey. Genet. Med. 9: 130-135.

Tunçbilek E (2001). Clinical outcomes of consanguineous marriages in Turkey. Turk. J. Pediatr. 43: 277-279.

Tunçbilek E, Boduroglu K and Alikasifoglu M (1999). Results of the Turkish congenital malformation survey. Turk. J. Pediatr. 41: 287-297.

WHO (1992). Manual for International Classification of Diseases and Health Related Problems. World Health Organization, Geneva.

WHO (1999). Services for the Prevention and Management of Genetic Disorders and Birth Defects in Developing Countries. Report of the Joint WHO/WAOPBD meeting (WHO/HGN/GL/WAOPBD/99.1). World Health Organization, Geneva.

WHO (2000). Primary Health Care Approaches for Prevention and Control of Congenital and Genetic Disorders (WHO/ HGN/WG/00.1). World Health Organization, Geneva.

WHO (2005). Control of Genetic Diseases (Executive Board EB116/3). World Health Organization, Geneva.

Yildiz S, Atalay A, Bağci H and Atalay EÖ (2005). Beta thalassemia mutations in Denizli province of Turkey. Turk. J. Haematol. 22: 19-23. 